\title{
Study on the Curriculum Assessment Reform in Agricultural Colleges and Universities
}

\author{
Chunfang Wang \\ School of Humanities, Jilin Agricultural University, Changchun 130118, China \\ wangchunfang1975@tom.com
}

\begin{abstract}
With the development of social economy, the reform of agriculture becomes very important, and it also puts forward new requirements for the reform of the course assessment of agricultural colleges and universities. The cultivation of talents is the ultimate goal of curriculum reform. Therefore, the reform of curriculum evaluation in agricultural colleges and universities is an inevitable requirement to adapt to the development of modern society. This paper, from the study on the current situation and problems of China's agricultural colleges and universities curriculum assessment, compares with the experience and enlightenment of foreign agricultural education curriculum system reform, analyzes the factors for the problems of curriculum assessment of China's agricultural universities, come to the guiding ideology of curriculum assessment reform in China agricultural colleges and universities, and then draws the conclusion of the research on the reform of curriculum evaluation in agricultural colleges and universities.
\end{abstract}

Keywords: Agricultural colleges and universities; Curriculum assessment; Guiding ideology; Reform.

\section{Introduction}

Entered in $21^{\text {st }}$ century, with the rapid development of science and technology, society is facing a huge change. Under the new economic and social development and new market changes, the development of win-win cooperation is the only choice. China has always been a big agricultural country, the development of agriculture plays a very important role in China's development, and agricultural problem is also related to people's livelihood issues around the world, so we must pay attention to the development of agriculture [1]. The advancement of agriculture is related to agricultural scientific and technological personnel that it depends on the creation and contribution of agricultural scientific and technological personnel. And the cultivation of agricultural scientific and technical personnel is mainly completed by the agricultural colleges and universities. The reform of agronomy professional course system is the inevitable requirement of the development of modern society, which has its profound social background and practical urgency, and Chinese agricultural colleges and universities thus speed up pace of the curriculum assessment reform.

\section{Research Background of Agricultural Education Curriculum Reform in Foreign Countries}

In higher education, general education and professional education are a pair of basic contradiction. The development of higher agricultural education in various countries always only pays attention to one aspect. For example, France attaches great importance to professional education. While in the United States, with the deepening reform of higher education, more and more educators advocate "all-embracing". Reaffirm the importance of general basic education and attaches importance to the development of professional education. For example, curriculum design of Massachusetts Institute of Technology includes natural science courses and humanities, arts and social science courses and communication course [2]. It mainly intends to expand students' thinking, let students, in the process of cognition, not only know the society, human knowledge and cultural knowledge, improve self-expression, and enhance social sensitivity. A person's academic ability is limited that it is impossible to master all the knowledge. Whereas, only with a strong basic knowledge of education 
can it be possible to enhance the ability of independent learning. Therefore, to strengthen basic education is an important choice to adhere to the change of higher agricultural education. When developing basic education, at the same time, it is necessary to pay attention to both developments of science and literature and mutual penetration, to enhance the understanding of natural science and social science knowledge [3]. Consequently, students agricultural professional also need to take courses in Humanities and social sciences, which is very necessary for students to enter the society to engage in a variety of professional communication activities after graduation.

\section{Current Research Situation and Problems of Curriculum Assessment in Agricultural Colleges and Universities}

\subsection{Low Scientific Degree of Curriculum System}

The establishment of professional curriculum system of agricultural colleges and universities in China, because of the lack of diversification of the main body, and the process of the programming excessive bias in the administrative, results in that the curriculum system is not scientific and reasonable. From relevant data and interviews of Shandong Agricultural University, it is concluded that our country lacks reasonable talent training scheme in agronomy professionals training. They just tend to be response to the Ministry of education and national policy, without real consideration of students' development, and many policies are just in the implementation stage, lack reasonable proof and scientific verification, so even if it is implemented, it is also very hard to see the effect.

According to the personnel organization of the curriculum system, many teachers are in a weak position to express their opinions. The major professional person in charge to determine the program and the expert can also guide, but it ignores the opinion of ordinary teachers who are nearest to the talents and mostly understand the students. From the process of curriculum system design, talent training is divided into two aspects: basic education courses and professional education courses, which seriously fragments the developing relationship between the two aspects [4]. Although the discipline expert has an insight in the curriculum and it is deep, because the academic atmosphere is too strong, it results in that it only has depth but no breadth, thus it cannot be well combined with reality.

\subsection{Ignorance of the Cultivation of Students' Ability}

With the continuous progress of the construction of new socialist countryside, there is an increasing need of practical talents who have certain professional knowledge and strong hands-on ability. However, higher agricultural education in China mainly takes the basic framework of the subject as the core, reflects the obvious subject features, but ignores the cultivation of emotion, attitude, ability, and values. In this paper, the graduates and students in school of the Shandong Agricultural University in recent years are taken as the object of investigation. Its statistical results are as follows:

Table 1 Whether the curriculum setting can satisfy the personnel training objectives

\begin{tabular}{|c|c|c|}
\hline & Basically satisfy & Dissatisfy \\
\hline Graduates & $51 \%$ & $29 \%$ \\
\hline Students in school & $49 \%$ & $34 \%$ \\
\hline
\end{tabular}

Many students in school believe that the curriculum needs to be optimized and the teaching materials need to update the case and content. Many graduates feel that the knowledge is not enough in practical work, the knowledge and structure ability is not enough, the theory and practice are out of touch, and the hands-on ability is poor in practical operation. In the survey of students in school, there are about $45 \%$ of the students think that, in the teaching process, it should focus on the training of practical ability; about $35 \%$ of the students think that both theory and practice are necessary to be emphasized. The employer believes that it not only needs a purely professional type of talent, but hope to possess both professional knowledge and professional skills [5]. It is hoped that the school can develop the students who have strong practical ability, broaden students' thinking, and strengthen the cultivation of students' comprehensive quality, especially the cultivation of practical ability. 


\subsection{Lack of Flexible Mechanism in Curriculum System}

Adhering to the dynamic open change and constant improvement of the structure of the curriculum system, which makes that classroom teaching assessment have a fresh life. However, at present, the course system of Agricultural Science in our country is too rigid and lack flexible mechanism. On the goal of education and curriculum, there is a fundamental difference between Dewey's and Taylor's value. Dewey thought that the purpose of education is from the process of experience activities and learning is the product of the activities. Taylor regarded that the aims of education is before experience and learning refers to specific intended, guiding and controlling results, which can be measured [6]. And we should adjust and choose the target according to the reality so that our curriculum system can be continuously improved in the dynamic implementation.

From the agricultural colleges and universities curriculum setting, the proportion of elective courses increases than that in the past, but it is not enough for providing enough space for students' self-design, as shown in Table 2.

Table 2 Required courses and elective courses in several agricultural universities in China (by the end of December 2015)

\begin{tabular}{|c|c|c|c|c|}
\hline & \multicolumn{2}{|c|}{ Required courses } & \multicolumn{2}{c|}{ Elective courses } \\
\hline & Credit & Proportion(\%) & Credit & Proportion(\%) \\
\hline Qingdao Agricultural University & 88.5 & 79 & 21.3 & 21 \\
\hline Henan Agricultural University & 109 & 74.5 & 35 & 25.5 \\
\hline Jilin Agricultural University & 119 & 78.9 & 33 & 21.1 \\
\hline Shandong Agricultural University & 118 & 76.4 & 38 & 23.6 \\
\hline
\end{tabular}

Notice: (1) Here the course only contains theoretical course. The practice course is not included.

(2) China Agricultural University practice set with modules and in each module there are a number of specific test items, for students to choose the experimental project autonomously. Therefore, the actual proportion of the elective course of the school is more than $30 \%$. For the convenience of comparison, it is not specially marked in the table 3.

Table 3 Cultivating objective of Agronomy profession in agricultural universities in China

\begin{tabular}{|c|c|}
\hline Universities & Cultivating objective of Agronomy profession \\
\hline Qingdao Agricultural University & $\begin{array}{c}\text { Cultivate production and management theory. Train technical and } \\
\text { operational personnel in the relevant units }\end{array}$ \\
\hline Henan Agricultural University & $\begin{array}{c}\text { Cultivate basic knowledge and technical and operational personnel } \\
\text { and compound talents in the relevant units }\end{array}$ \\
\hline Jilin Agricultural University & $\begin{array}{c}\text { Cultivate basic knowledge, develop skills, and train senior } \\
\text { scientific and technical personnel }\end{array}$ \\
\hline Shandong Agricultural University & $\begin{array}{c}\text { Cultivate the basic theory, basic knowledge and skills of } \\
\text { management, as well as advanced science and technology } \\
\text { personnel }\end{array}$ \\
\hline
\end{tabular}

\subsection{Lack of Internationalization Degree of the Curriculum System}

In recent years, the internationalization of higher education has become a global trend. International education has enriched human society from many aspects, and it has deepened the mutual cognition and understanding among different cultures. At the same time, with the continuous improvement of the world's agricultural globalization and the extension of the connotation of modern agriculture, modern agricultural practitioners will face more and more frequent international cooperation and exchange. Therefore, the modern agriculture has a higher and higher requirement on its practitioners' international awareness, international vision, international trade and other relevant laws and regulations. However, from the current situation, the degree of internationalization of agricultural professional course system is generally not high. From the point of view of the curriculum system goal, overview China Agricultural University, Nanjing Agricultural University, Huazhong Agricultural University and Sichuan Agricultural University, all have basic specifications and quality requirements on students in Agronomy profession, and the overall goal of the curriculum system are basically the same [7]. There is no mention of the "international concept of students, international 
vision and awareness of globalization" goal, and the lack of this goal becomes a universal phenomenon in universities of agriculture professional curriculum system objectives.

From the course implementation, these courses are confined to the classroom interpretation, rarely related to analyze these issues from the perspective of the world of ideas and methods.

\section{Analysis on the Causes of the Problems of Curriculum Assessment in Agricultural Colleges and Universities}

\subsection{Influence of Educational Concept}

The idea of our country's education is to cultivate high, fine, and wise professional talents. It is necessary to pay attention to professional education, while basic education is relatively weak. The teaching of knowledge is taken as the main purpose, but do not pay attention to practical education nor pay attention to cultivation of students' ability, emotion and other basic qualities. The unified teaching can unify the knowledge standard, but limits the development of students' individual ability. Although the reform of higher education has been aware of these issues and tried to correct, due to the restriction of developing patterns of Agricultural Colleges, it makes the school still moving in the direction of academic, and thus dilutes the teaching of education theory and practical skills [8]. Therefore, to build a scientific curriculum system, we must pay more attention to the construction of curriculum system, strengthen the cultivation of personnel in curriculum system to promote the improvement of teacher education theoretical level and practical ability.

\subsection{Effect of Educational Mechanism}

In our country, the setting of curriculum system in Colleges and universities is mainly guided by the administrative departments, and draw a conclusion with the discussion of experts as the main body and teachers as supplement. The main method of design is to see what each expert wants students to learn, rather than to investigate the idea of student, nor to consult what kinds of talents employers need, let alone to survey what kind of talent they need in agricultural field. Eventually it results in that the curriculum is unreasonable and the lack of talent learning content. It will also cause that the employing unit cannot find practical talents and compound talents. In the end, students can only learn the knowledge of professional theory, but the thinking field becomes narrower.

\section{Research Result on the Curriculum Assessment Reform in Agricultural Colleges and Universities}

\subsection{Trend Requirement of the Development of Agricultural Globalization}

There are many new situations and new trends in the process of the development of agricultural globalization. Under the impetus of economic globalization, the economic exchanges among countries are frequent, and so do the agricultural culture and technical exchanges and cooperation. In this international environment, we must put our country agriculture in the pattern of the world and identify the location, identify the development direction, understand the new trends in the development of agriculture in other countries, grasp the new trends of world agriculture development, continuously improve the overall quality and comprehensive strength of the agriculture of our country, enhance the core competitiveness of our country agriculture, and accelerate the modernization of our country agriculture. Generally speaking, the current trend of world agricultural development includes five aspects, namely, the new technological revolution, food safety including the safe quality, integrated management, trade liberalization and sustainable development.

\subsection{Urgent Requirements for the Construction of New Rural Areas}

The new socialist countryside construction is an important measure to build a well-off society in an all-round way in the $21^{\text {st }}$ century, which mainly intends to realize the modernization of the rural areas. It needs to not only enable rural productivity greatly improved, but also make the rural production relations and superstructure development more harmonious and perfect, including strengthen rural socialist economic construction, political construction, cultural construction, harmonious social construction and Party construction in an all-round way. And the realization of these goals mainly rely 
on the high quality new rural constructors, so eventually it needs that the agricultural colleges and universities prepares for the cultivation of talents, and changes the past single talent training mode [9]. Therefore, in order to continuously push forward the cause of building the socialist new countryside, agricultural colleges and universities must accelerate the pace of reform, cultivate a large number of high-quality agricultural science and technology personnel as soon as possible, and guide them to actively participate in the new rural construction, to show their talents in the promotion of agricultural science and technology, the development of agricultural industrialization, management of modern agriculture, rural cultural construction aspect, and to make great contributions.

\subsection{Requirements for Deepening Reform of Higher Education}

Development of agricultural colleges and universities needs to be advanced with the times. In the meanwhile, according to the needs of social and economic development and scientific and technological progress, it needs to update teaching contents, adjust the system of curriculum assessment, promptly add new knowledge, new theory and new technology to the teaching content, so students can quickly access to the most advanced and timely knowledge and skills. Provide students with curriculum system and teaching content that meet the needs of the times. Vigorously promote teaching methods reform and curriculum evaluation model improvement. Advocate way of inspiring students' thinking, pay attention to the personal development, and attach importance to teach students in accordance with their aptitude. Optimize the curriculum structure, construct the curriculum system that combines core courses with elective courses, which is conducive to the cross and integration of subjects. Efforts should be made to improve college students' learning ability, innovation ability, practical ability, communication ability and social adaptation ability.

Facing the situation of the reform of higher education, as an important part of higher education, the agricultural colleges and universities must quicken the pace of education, actively seek new models, and seek development in the reform. As the main body and traditional profession of agricultural colleges, the reform of the curriculum system is more practical and important. To enhance the comprehensive ability of students and further clarify and emphasize their mode of development is the urgent requirements for national economic and social development of higher education personnel training. And as a profession that has strong practicality and application feature, for Agronomy profession, its comprehensive ability of students, especially the cultivation of practical ability is in an important position in the general specification of its personnel cultivation.

\section{Conclusion}

At first, this paper analyzes the present situation and problems of curriculum assessment reform in China's Agricultural Colleges and universities, learns that current curriculum system is low in scientific degree, ignoring the students' ability training, curriculum system lacking flexibility mechanisms, and lacking internationalization degree and features and so on. According to the advanced experience of the development of advanced agricultural colleges and universities in foreign countries, the enlightenment to our country is discussed, and the main reasons for the present situation of our country are deeply analyzed. Through the analysis of the reasons, find the guiding ideology for solving the problem, as well as the practical and feasible basis for making these changes. Ultimately determine the trend of the development of agricultural globalization and the urgent requirements of the new rural construction. Our country must pay attention to the reform of curriculum assessment.

\section{References}

[1] Willis J, Adie L, Klenowski V. Conceptualising teachers' assessment literacies in an era of curriculum and assessment reform [J]. The Australian Educational Researcher, 2013, 40(2): 241-256.

[2] So K, Kang J. Curriculum reform in Korea: Issues and challenges for twenty-first century learning [J]. The Asia-Pacific Education Researcher, 2014, 23(4): 795-803. 
[3] East M. Coming to terms with innovative high-stakes assessment practice: Teachers' viewpoints on assessment reform [J]. Language Testing, 2014: 0265532214544393.

[4] Mills M, McGregor G. Learning not borrowing from the Queensland education system: lessons on curricular, pedagogical and assessment reform [J]. The Curriculum Journal, 2016, 27(1): 113-133.

[5] Woods A, Dooley K, Luke A, et al. School leadership, literacy and social justice: The place of local school curriculum planning and reform $[\mathrm{M}] / /$ International handbook of educational leadership and social (in) justice. Springer Netherlands, 2014: 509-520.

[6] Dong W, Deng X. Some measures of teaching reform of mathematical analysis in agricultural colleges[C]//Information Engineering and Education Science: Proceedings of the International Hu P E I, Bang-song Y A O. Practical Teaching Base Management Mode of Water and Soil Specialty in Agricultural Colleges and Universities [J]. Value Engineering, 2013, 14: 128.

[7] Gholifar E, Gholami H. The study of affecting factors on faculty members' psychological empowerment: An investigation in the Iran's agricultural colleges [J]. Journal of Applied Research in Higher Education, 2014, 6(1): 63-74.

[8] JIA X, LIU B, LU M. On The Construction of Dormitory Culture of Graduate Students in Agricultural Colleges and Universities_—an Empirical Investigation and Analysis of Graduate Students of Huazhong Agricultural University [J]. Journal of Shenyang Agricultural University (Social Sciences Edition), 2013, 5: 015.

[9] Hu P E I, Bang-song Y A O. Practical Teaching Base Management Mode of Water and Soil Specialty in Agricultural Colleges and Universities [J]. Value Engineering, 2013, 14: 128. 